\title{
Simultaneous Removal of Harmful Algal Blooms and Microcystins Using Microorganism- and Chitosan-Modified Local Soil
}

\author{
Hong $\mathrm{Li}^{\dagger \dagger}$ and Gang Pan* ${ }^{\dagger}$ \\ ${ }^{\dagger}$ Research Center for Eco-environmental Sciences, Chinese Academy of Sciences, 18 Shuangqing Road, Beijing 100085, China \\ ${ }^{\ddagger}$ Institute of Biology, Guizhou Academy of Science, Guiyang 550009, China
}

\section{Supporting Information}

ABSTRACT: Cyanobacterial harmful algal blooms (cyano-HAB) and microcystins (MCs) can cause a potential threat to public health. Here, a method for simultaneous removal of cyano-HAB and MCs was developed using chitosan-modified local soil (MLS) flocculation plus microorganism-modified soil capping. The experiment was conducted in simulated columns containing algal water collected from Lake Taihu (China). More than $90 \%$ of algal cells and intracellular MCs were flocculated and removed from water using chitosan-MLS and the sunken flocs were treated by different capping materials including Pseudomonas sp. An18 modified local soil. During 40 days of incubation, dissolved MC-LR and MC-RR showed 10-fold increase in the flocculation-only system. The increase of MC-LR and MC-RR in water was reduced by 30 and $70 \%$ in soil capping treatments; however, the total content of MCs in the sediment-water column remained

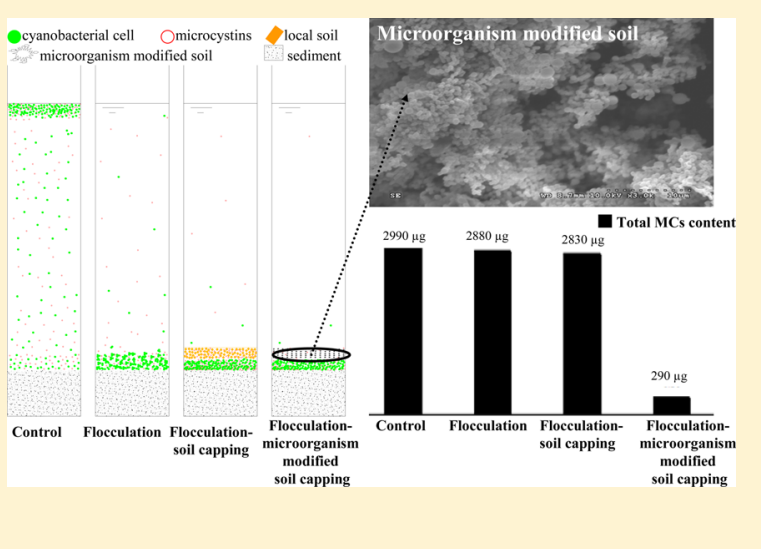
similar to that in the control and flocculation only systems. In contrast, both dissolved MCs and total MCs were reduced by $90 \%$ in Pseudomonas sp. An18 modified soil capping treatment. The high performance of toxin decomposition was due to the combined effects of flocculation and MC-degrading bacteria that embedded in the capping material, which prevents dilution of bacteria biomass, concentrates algal cells, confines released toxins, and enhances toxin biodegradation.

\section{INTRODUCTION}

Cyanobacteria harmful algal blooms (cyano-HABs) have increasingly occurred worldwide in various water sources, ${ }^{1}$ and one of the negative consequences is the production of cyanotoxins. ${ }^{2}$ Microcystins (MCs) are frequently encountered cyanotoxins that contain over 90 variants. ${ }^{3}$ MCs are primarily retained in algal cells but are released into waters as a result of cells lysis. ${ }^{4}$ They can be accumulated in aquatic life ${ }^{5}$ or transferred to higher trophic levels, ${ }^{6}$ which presents a potential threat to public health because they are tumor promoters. ${ }^{7}$ Therefore, rapid and sustainable degradation of MCs is imperative during the mitigation of cyano-HABs in natural waters.

Several methods including the application of algaecides and chemical and clay flocculation have been tested to remove cyano-HABs in natural waters, ${ }^{8-10}$ whereas the methods often result in release of intracellular MCs into water. ${ }^{11}$ Removal of extracellular MCs using activated carbon, plant-mineral composite, and phoslock are investigated; ${ }^{12-14}$ however, in addition to the high cost for large-scale application, these methods only transfer MCs from water to other media, ${ }^{15}$ and excessive amount of MCs could return to water column. Only when MCs are degraded to less toxic products can the negative affects be diminished. ${ }^{16}$ Pan et al. propose a chitosan Modified Local Soil Induced Ecological Restoration (MLS-IER) technology to flocculate algal cells and then convert them into submerged vegetation in shallow waters. ${ }^{17}$ However, the released toxins could be diffused or mixed back to water column in deep water system where submerged macrophytes cannot be restored. MCs are degradable in natural waters by a wide range of microorganisms; ${ }^{5,18}$ however, MCs may not be rapidly degraded by indigenous microorganisms if massive intracellular MCs are released due to the intensive lysis of the settled algal cells. ${ }^{19}$ Embedding exogenous MCs-degrading bacteria in the capping layer provide a potential alternative to enhance the biodegradation of MCs. However, challenges are presented due to the poor adaptability of MC-degrading bacteria obtained through conventional artificial culture media (mostly in mineral salts), where the isolated bacteria often cannot form sustainable colonies and continuously degrade MCs in natural waters. ${ }^{20,21}$

Aiming at improving bacterial adaptability, we have previously proposed a method to isolate MC-degrading bacteria using concentrated water extract of sediment as natural culture media. ${ }^{21}$ It was proved that the obtained strain Pseudomonas sp. An18 displayed enhanced and continuous degradation of MCs in collected Lake Taihu water under continuous addition of

Received: February 15, 2015

Revised: April 15, 2015

Accepted: April 22, 2015

Published: April 22, 2015 
MCs. ${ }^{21}$ We anticipate that if Pseudomonas sp. An18 is embedded into the capping materials, it may greatly enhance the decomposition of MCs following MLS flocculation, since both the toxins and the bacteria can be well confined under the capping layer, and the increased availability of MCs and improved bacterial adaptability may work together to enhance the biodegradation of MCs. So far, there are no previous studies of embedding sustainable microorganisms into the capping materials and its combination to MLS flocculation-capping method for simultaneous removal of cyano-HABs and degradation of MCs.

In this study, microorganism-modified capping materials were prepared by embedding Pseudomonas sp. An 18 into Lake Taihu local soil. Simulated column experiment containing Lake Taihu water was conducted to evaluate the effect of chitosanMLS flocculation followed by Pseudomonas sp. An18 modified soil capping on the removal of algal cells and degradation of MC-RR and MC-LR. The objective is to study the effect and the mechanism on cyano-HABs removal and MCs degradation using MLS flocculation and capping method.

\section{MATERIALS AND METHODS}

Toxin Standards and Reagents. MCs standards (MC-RR and MC-LR) were obtained from Taiwan Algal Science, Inc. (purity $\geq 95 \%$ by HPLC). Enkephalin (internal standard) was purchased from Sigma-Aldrich.

Soil and Modifier. The soil used in flocculation experiment was collected from the bank of Meiliang Bay of Lake Taihu at Wuxi, washed with distilled water, and dried for $10 \mathrm{~h}$ at $90{ }^{\circ} \mathrm{C}$. The soil was sieved through 180 mesh $(74 \mu \mathrm{m})$. Chitosan (solid) was obtained from Qingdao Haisheng Bioengineering Co., Ltd. The molecular weight of chitosan was 500000 , and the deacetylation degree was $83.6 \%$. Deionized water was prepared using a Milli-Q filtration system (Millipore, Bedford, MA).

Preparation of Chitosan Modified Soil. Chitosan was dissolved by adding $100 \mathrm{mg}$ of chitosan to $10 \mathrm{~mL}$ of $1 \% \mathrm{HCl}$ and mixing until all chitosan was dissolved. This solution was diluted with deionized water to obtain a working solution of 1 $\mathrm{mg} / \mathrm{mL}$. To modify the soils, we added a certain volume of chitosan working solution to soil suspension. The mixture was well stirred and then ready for use in the flocculation experiment. The SEM picture of chitosan modified soil was presented in our previous study. ${ }^{22}$

Preparation of Microorganism Modified Soil. Local soil was collected from the shore of Lake Taihu (Meiliang Bay, Wuxi, China) and sieved through 40 mesh. Pseudomonas sp. An18 was isolated through water extract of sediment followed by concentration treatment according to the method described in our previous study. ${ }^{21}$ The bacteria were incubated in mineral salts medium containing MC-RR $(50 \mu \mathrm{g} / \mathrm{L})$ and MC-LR (6 $\mu \mathrm{g} / \mathrm{L})$ for 3 days, then harvested by centrifugation at 10000 rpm for $5 \mathrm{~min}$, and washed twice with $50 \mathrm{mM}$ phosphate buffer ( $\mathrm{pH} 7.0)$. The local soil were dried in muffle furnace at $250{ }^{\circ} \mathrm{C}$ for $3 \mathrm{~h}$, then the resultant soil $(10 \mathrm{~g})$ was mixed with $150 \mathrm{~mL}$ Pseudomonas sp. An 18 suspensions $\left(5 \times 10^{13} \mathrm{CFU} / \mathrm{mL}\right)$ in 250 $\mathrm{mL}$ Erlenmeyer flask with shaken at $150 \mathrm{rpm}$ for $4 \mathrm{~h}$. The suspension solution was centrifuged at $7000 \mathrm{rpm}$, and the precipitate was washed three times with sterile water; finally, 1 $\mathrm{M} \mathrm{NaCl}$ was added to liberate the weakly retained bacterial cells. $^{23}$ The modified soil was capable of embedding $10^{15}$ bacterial cells/g-soil. The evaluation of Pseudomonas sp. An 18 proliferation in the modified soil was conducted in mineral salt medium with addition of filter sterilized MCs every 2 days, ${ }^{20}$ the microorganism-modified soil was vortexed to detach the embedded Pseudomonas sp. An18 from soil, and the bacteria number were counted using plate counting method.

Incubation Experiment. The experiment was conducted in $2000 \mathrm{~mL}$ plexiglass columns (diameter, $8.4 \mathrm{~cm}$ ). The Taihu local soil was autoclaved and used as sediment in the column. A volume of $1500 \mathrm{~mL}$ cyano-HABs water was collected from Meiliang Bay, Lake Taihu and added into the columns (the initial algae concentration was $1.38 \times 10^{10}$ cells/L, and the concentrations of MC-RR and MC-LR were 5.14 and $0.84 \mu \mathrm{g} /$ $\mathrm{L}$, respectively). Twelve columns containing the same amount of sediment and algal water were prepared. Three were used as controls where no flocculants or capping materials were added. Chitosan-modified local soil (2 mg/L chitosan and $100 \mathrm{mg} / \mathrm{L}$ soil; this optimized dosage was obtained according to jar test presented in Figures S1 and S2, Supporting Information) was added to the rest of the columns and then followed by three different capping treatments. No capping materials were added in the flocculation-only systems (three columns). Among the rest of the columns, the flocculated algal flocs were capped with $1 \mathrm{~cm}$ local soil (three columns) or $1 \mathrm{~cm}$ Pseudomonas sp. An 18 modified soil (three columns). The 12 columns were incubated at $25{ }^{\circ} \mathrm{C}$ with an alternating cycle of $12 \mathrm{~h}$ of light and $12 \mathrm{~h}$ of darkness for 40 days.

Sample Collection and Preparation. Water samples were collected at $1 \mathrm{~cm}$ below the water surface every 3 days. After filtration through a $0.22 \mu \mathrm{m}$ membrane, the water was spiked with $100 \mu \mathrm{L}$ enkephalin internal standard $(10 \mu \mathrm{g} / \mathrm{L})$ to reduce the matrix effects during measurement of MCs. ${ }^{24}$ The algal cells were enumerated every 3 days. After 40 days of incubation, to assess the distribution of MC-RR and MC-LR in different parts of the sediment-water systems, we carefully took off the overlaying water from each column and filtered it through a $0.45 \mu \mathrm{m}$ membrane to separate the suspended algal cells. The sediment in the columns was sliced into three sections: $0-1 \mathrm{~cm}$ (capping layer), $1-2 \mathrm{~cm}$ (flocs layer), and $2-6 \mathrm{~cm}$ (sediment layer). For the control system, there were no capping and flocs layers. The capping layer (local soil or Pseudomonas sp. An 18 modified soil) and sediment layer were freeze-dried and extracted in $0.1 \mathrm{M}$ EDTA- $\mathrm{Na}_{4} \mathrm{P}_{2} \mathrm{O}_{7}$ three times. After centrifugation at $4000 \mathrm{rpm}$, the aqueous extractions were passed through SPE cartridge ( $300 \mathrm{mg}, 3 \mathrm{~mL}$, Waters), and the eluted solution was evaporated under nitrogen and dissolved in $1 \mathrm{~mL}$ of distilled water for UPLC-MS/MS analysis. ${ }^{25}$ Suspended algal cells and algae flocs were freeze-dried and extracted using a $40 \%(\mathrm{v} / \mathrm{v})$ methanol solution with ultrasonication $(300 \mathrm{~W}, 5 \mathrm{~min})$ three times, followed by the evaporation of the elution containing MCs from SPE cartridge, as was described previously. ${ }^{26}$ The total content $(\mu \mathrm{g})$ of MCLR and MC-RR in the whole systems after 40 days of incubation were calculated according to the toxin concentration in filtered water, suspended algae cells and that in sediment, flocs layer, and capping layer (dry weight).

MCs Determination. Quantitative analysis of MCs was performed using a LC-MS system equipped with electrospray ionization tandem mass spectrometry (UPLC-ESI-MS/MS) (Acquity UPLC, Quattro Premier XE, Waters). Sample separation was carried out with UPLC system and Acquity UPLC BEH C ${ }_{18}$ column (i.d. $2.1 \times 50 \mathrm{~mm}$, particle size $1.7 \mu \mathrm{m}$, pore size $130 \AA$, Waters). The column oven was kept at $40^{\circ} \mathrm{C}$ and the injection volume was $10 \mu \mathrm{L}$. The flow rate used was 0.2 $\mathrm{mL} / \mathrm{min}$. Water and acetonitrile were used as mobile phases, 

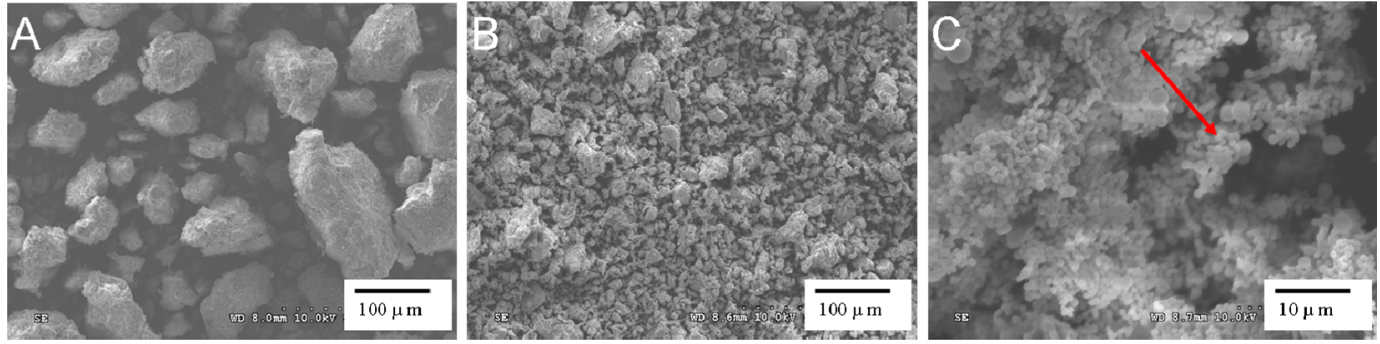

Figure 1. SEM photographs of local soil and Pseudomonas sp. An18 modified soil: (A) local soil $(200 \times$ magnification), (B) Pseudomonas sp. An18 modified soil (200× magnification), (C) Pseudomonas sp. An18 modified soil (3000× magnification). The arrow in panel C points to Pseudomonas sp. An18.

the organic phase was linearly increased from 45 to $60 \%$ in 2.5 min, then increased to $100 \%$ in $1.5 \mathrm{~min}$ and held for $0.5 \mathrm{~min}$, and finally brought back to $45 \%$ and held for $3 \mathrm{~min}$ until the next injection. The mass spectrometer was operated in positive mode electrospray ionization in multiple-reaction monitoring mode. Source temperature and desolvation gas temperature were held at 120 and $350{ }^{\circ} \mathrm{C}$, respectively. The measured recoveries of the method ranged between 91.0 and $103.2 \%$. The detection limit was 6.0 and $3.0 \mathrm{ng} / \mathrm{L}$ for MC-RR and MC-LR, respectively.

Analysis of MCs Biodegradation Products. Biodegradation products of the toxins were analyzed using matrix-assisted laser desorption/ionization-time-of-flight mass spectrometry (MALDI-TOF MS, BIFLEX III, Bruker, Inc.). After 40 days of incubation, MCs from the sediment of local soil capped system and Pseudomonas sp. An18 modified soil capped system were extracted. The extracted MC solution (containing MCs and its degradation products) was dried with nitrogen, then dissolved in distilled water. MALDI-TOF-MS instrument was equipped with a nitrogen laser operating at $337 \mathrm{~nm}$, and a twostate ion source operating in the delayed extraction mode. Briefly, $2 \mu \mathrm{L}$ of a saturated solution of $\alpha$-cyano-4-hydroxycinnamic acid (in $3: 2 \mathrm{v} / \mathrm{v}$ acetonitrile $-0.1 \%$ trifluoroacetic acid) were premixed with $2 \mu \mathrm{L}$ of the MCs solution. Afterward, $2 \mu \mathrm{L}$ of this mixture were applied to the sample plate and air-dried at $24{ }^{\circ} \mathrm{C}$. Measurements were performed at an acceleration voltage of $20 \mathrm{kV}$ using reflector mode, which enabled the determination of monoisotopic mass values. Each spectrum refers to the sum of 100-200 individual laser shots.

Soil Characterization. Micrographs of soil and microorganism modified soil were characterized using a XL-30 scanning electron microscope (Philips Corp., The Netherlands).

Statistical Analysis. The $t$ test was used to determine significant differences among different measurements; a significance was assumed when $P<0.05$.

\section{RESULTS}

Soil Characterization. Scanning electron microscope (SEM) images showed a smooth surface and discrete particles of local soil particles (Figure 1A), while modification by Pseudomonas sp. An18 substantially roughened the surface of the soil with widely distributed ridges and a large density of Pseudomonas sp. An 18 (Figure 1B,C). Evaluation of Pseudomonas sp. An 18 carrying capability revealed the modified soil was capable of embedding $10^{15}$ bacterial cells/g soil (Figure S3, Supporting Information). Proliferation tests showed that the biomass of Pseudomonas sp. An18 in the microorganismmodified soil dramatically increased after a 1 day lag phase and yielded stable CFU counts (nearly $10^{19} \mathrm{CFU} / \mathrm{mL}$ ) after 3 days (Figure 2), suggesting the soil was favorable for Pseudomonas sp. An 18 growth when MCs were supplied.

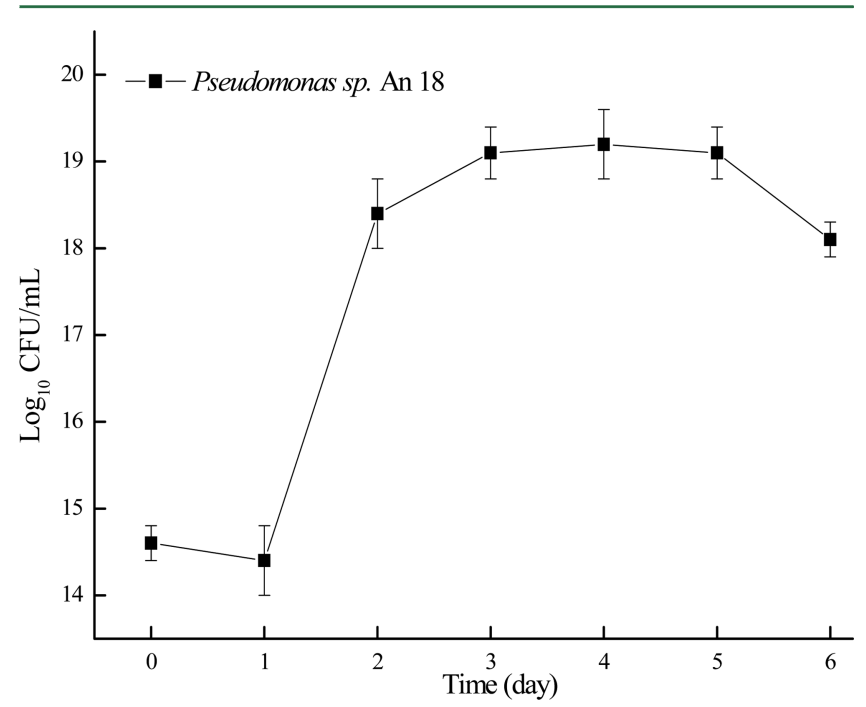

Figure 2. Proliferation of Pseudomonas sp. An18 on the microorganism modified soil in mineral salts medium containing MCs. Data represent the mean values of triplicate \pm SD.

Algae Removal. In the chitosan-MLS flocculation only systems, the algae removal rate reached 99\% within 1 day; however, resuspension of algal cells occurred in the following days, and the removal rate reduced to about $90 \%$ at day 40 (Figure 3). The resuspension was effectively avoided when local soil or Pseudomonas sp. An18 modified soil was used to cap the sunken algae flocs, where the removal rate remained at $99 \%$ throughout the 40 day period. A small algae removal (maximum of $13 \%$ at day 40 ) was also observed in the control systems (Figure 3).

MCs in Water Column. The initial concentration of dissolved MC-RR in the Taihu water sample was $5.14 \mu \mathrm{g} / \mathrm{L}$. In the control systems, an obvious increase of dissolved MC-RR was observed from day 9, which reached the maximum level of $108.14 \mu \mathrm{g} / \mathrm{L}$ between days 24 and 40 that is 20 -fold higher than the initial level (Figure 4A-a). Compared to the control systems, the increase of dissolved MC-RR was reduced by $50 \%$ in chitosan-MLS flocculation only systems (Figure 4A-b), 70\% in flocculation-local soil capping systems (Figure 4A-c), and 96\% in flocculation plus Pseudomonas sp. An18 modified soil capping systems (Figure 4A-d), respectively. The dissolved MC-LR showed a similar trend with that of MC-RR among different treatments. The initial concentration of dissolved MC- 


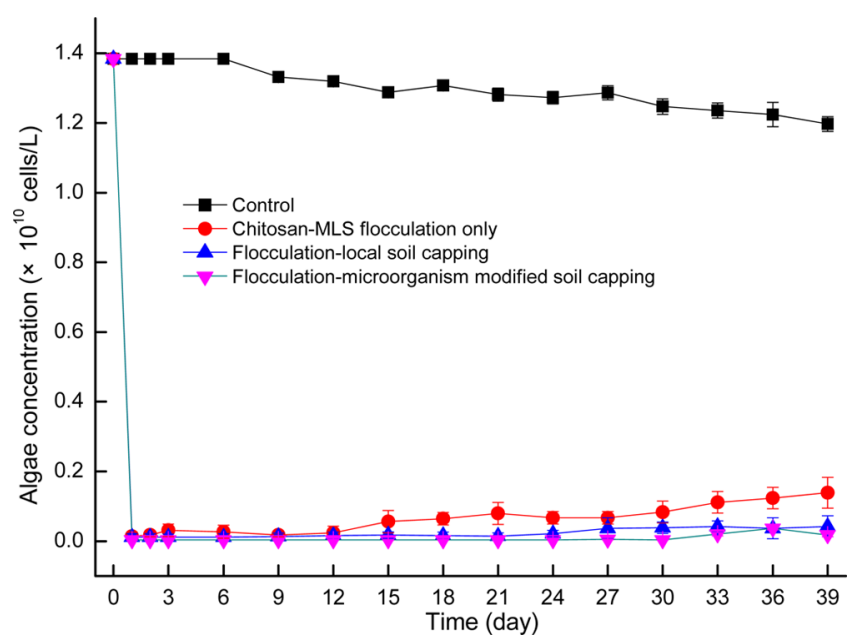

Figure 3. Changes in algae concentration in water columns. Data represent the mean values of triplicate $\pm \mathrm{SD}$.

LR in Taihu water sample was $0.84 \mu \mathrm{g} / \mathrm{L}$. In the control systems, dissolved MC-LR was quickly increased from day 9 to day 24 and reached $15.45 \mu \mathrm{g} / \mathrm{L}$ between day 24 to 40 (Figure $4 \mathrm{~B}-\mathrm{a})$. At day 40, the MC-LR release was reduced to $10.64 \mu \mathrm{g} /$ $\mathrm{L}$ by chitosan-MLS flocculation-only treatment (Figure 4B-b), $6.65 \mu \mathrm{g} / \mathrm{L}$ by flocculation plus local soil capping treatment (Figure $4 \mathrm{~B}-\mathrm{c}$ ), and $0.49 \mu \mathrm{g} / \mathrm{L}$ by flocculation plus Pseudomonas sp. An18 modified soil capping treatment (Figure 4B-d), respectively. The diffusion of released MCs from sediment to water were largely reduced in soil capping treatment (Figure $4 \mathrm{~A}-\mathrm{c}, \mathrm{B}-\mathrm{c})$ and entirely disappeared in microorganism-modified soil treated systems (Figure 4A-d,B-d).

Distribution of MCs. Measurements of MCs in water, algae cells, sediment, flocs, and capping layer illustrated the distribution of MCs in different parts of the sediment-water column systems. For the control systems, among the total MC$\mathrm{RR}(2360 \mu \mathrm{g}), 51 \%$ of the intracellular MC-RR $(1209 \mu \mathrm{g})$ was released into the water, $48 \%$ was still left in suspended algal cells $(1135 \mu \mathrm{g}$ ), and $1 \%$ in the sediment at day 40 (Figure 5Aa). Chitosan-MLS flocculation transferred $85 \%$ of the MC-RR into the sunken algal flocs and left $10 \%$ in suspended algae cells and $4 \%$ in water (Figure 5A-b). In the flocculation and soil capping treatment, MC-RR was almost entirely removed from suspended algae cells and water (2\% left), $78 \%$ and $19 \%$ were transferred into the flocs layer and capping layer, respectively, (Figure 5A-c). However, the total content of MC-RR in the flocculation-only and flocculation-soil capping systems remained similar to that of the control. In contrast, nearly $90 \%$ MC-RR in the whole sediment-water system was degraded in chitosan-MLS flocculation plus Pseudomonas sp. An18 modified soil capping systems (Figure 5A-d), and the dissolved MC-RR left in the water $(6 \mu \mathrm{g})$ was reduced by 201-, 13-, and 5-fold compared to the control, flocculation only, and flocculationsoil capping systems, where the original total content of toxins were similar. The distribution of MC-LR followed a similar pattern with that of MC-RR. The dissolved MC-LR in the control was $356 \mu \mathrm{g}$ (Figure 5B-a) and was reduced to 23 and 10 $\mu \mathrm{g}$ in flocculation (Figure 5B-b) and flocculation-soil capping systems (Figure 5B-c), respectively, but the total MC-LR content $(620-650 \mu \mathrm{g})$ remained similar among these three systems (Figure 5B). In contrast, the total MC-LR content was reduced by $90 \%$ and dissolved MC-LR by $99 \%$ in flocculation plus Pseudomonas sp. An18 modified soil capping treatment (Figure 5B-d) compared to the control systems.

Biodegradation Products of MCs. The MS spectrum of MC-RR revealed a major ion at $\mathrm{m} / z 1038.27$ after 40 days incubation in soil capped sediment (Figure 6a), in contrast, two major degradation products of MC-RR $\left(M_{w}=332.92\right.$ and 707.27) were observed in Pseudomonas sp. An18 modified soil capped layer (Figure 6b), corresponding to the reduced intensity of MC-RR $\left(M_{\mathrm{w}}=1038.27\right)$. Similarly, In comparison to the great intensity of MC-LR in soil capped sediment (Figure 6c), the predominate ion in Pseudomonas sp. An18 modified soil capped layer converted to $M_{\mathrm{w}}=332.73$ and 301.65 (Figure 6d), of which the MC-LR ion at $\mathrm{m} / z 995.83$ almost disappeared.
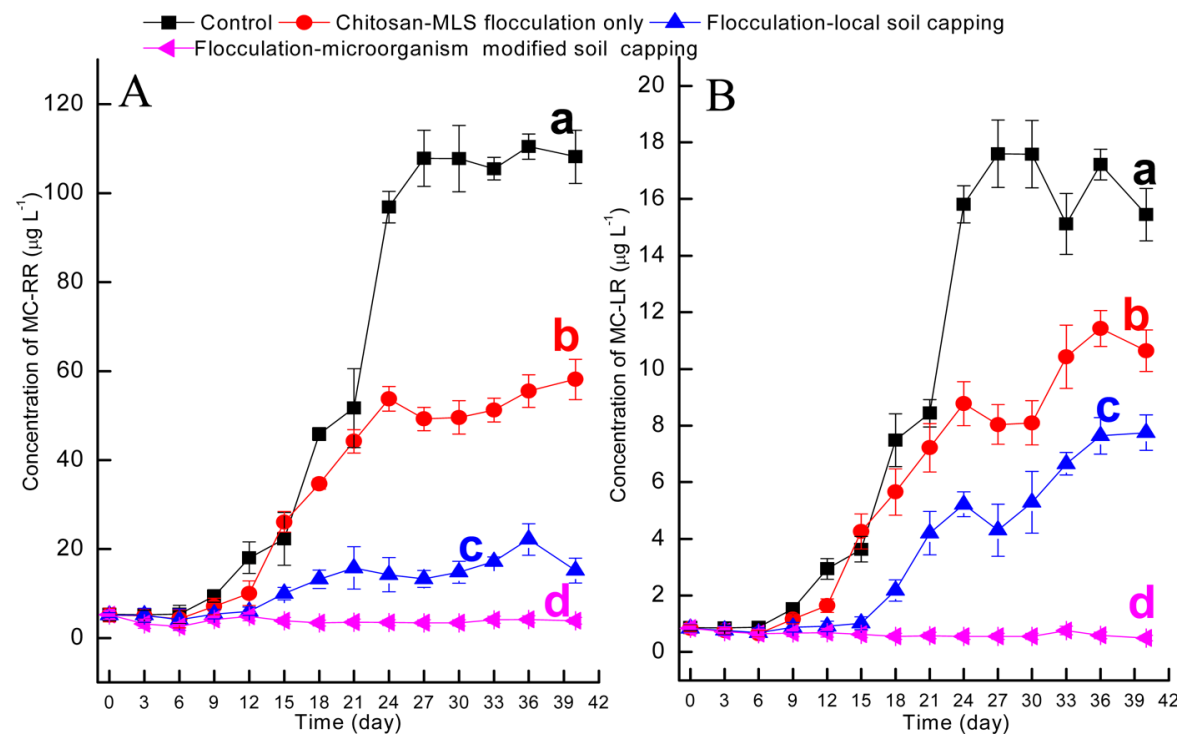

Figure 4. Changes of dissolved (A) MC-RR and (B) MC-LR concentration in the surface water of different systems; a, b, c, and d indicate different treatments as noted in the legend above the graphs. Data represent the mean values of triplicate \pm SD. 

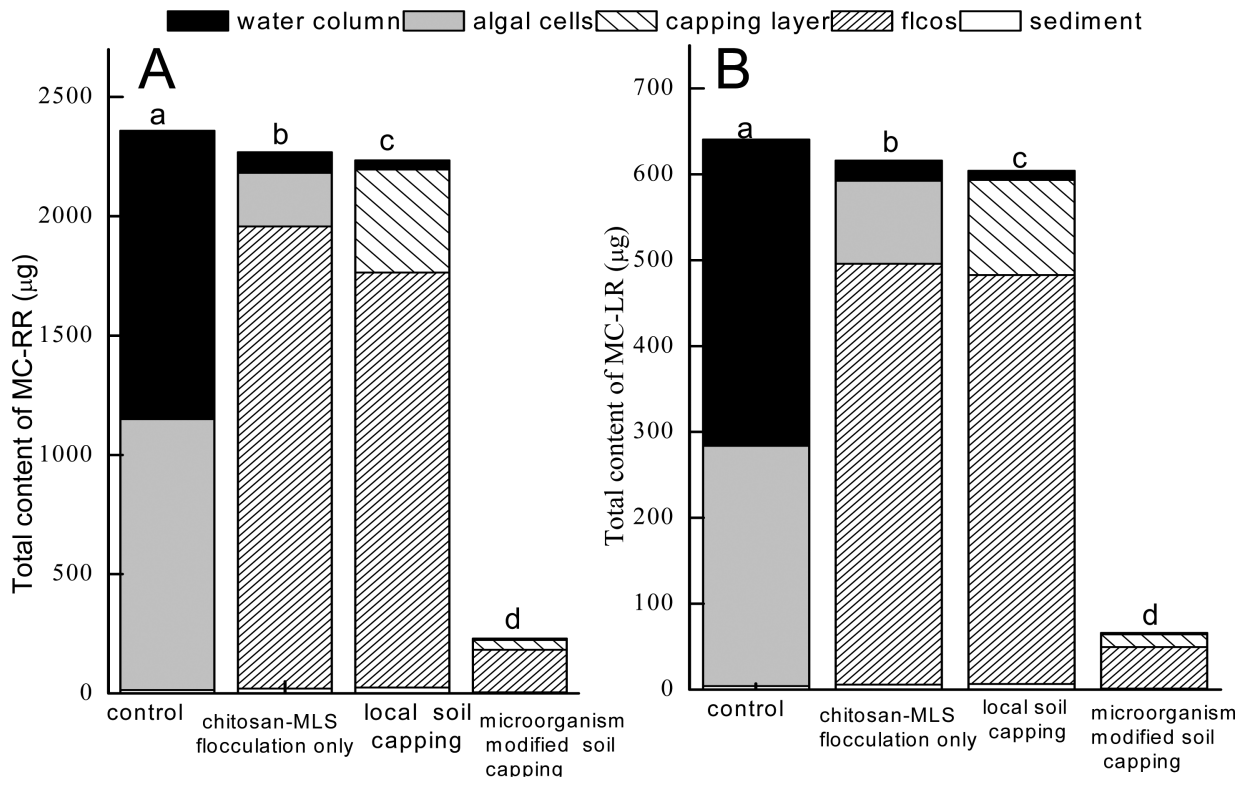

Figure 5. Distribution of total content of (A) MC-RR and (B) MC-LR in different parts of the sediment-water system of each treatment after 40 days of incubation. Data represent the mean values of triplicate.
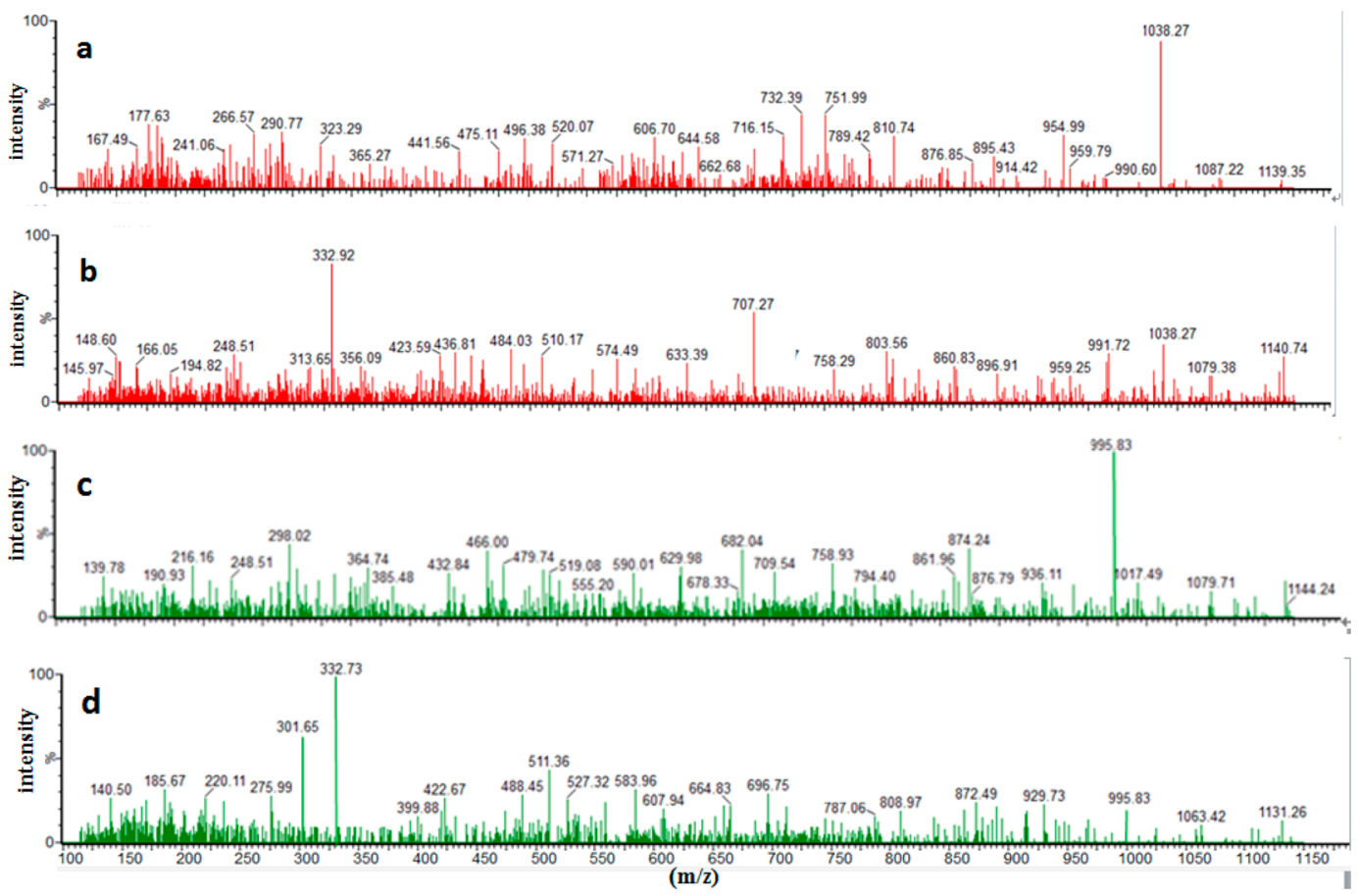

Figure 6. Mass spectra of (a) MC-RR in the sediment of soil capping layer after 40 days incubation, (b) MC-RR and its biodegradation products after 40 days in the sediment of Pseudomonas sp. An18 modified soil capped layer, (c) MC-LR in the sediment of soil capping layer after 40 days incubation, and (d) MC-LR and its biodegradation products after 40 days in the sediment of Pseudomonas sp. An18 modified soil capped layer.

\section{DISCUSSION}

Effect of Flocculataion and Capping on Algae and Toxin Removal. Algal cells tend to suspend and float in water because of the negatively charged cell surface, low specific gravity, and specific buoyant structure. Chitosan, a cellulose-like polyelectrolyte biopolymer, is derived from the alkaline deacetylation of crustacean chitin, which possesses several intrinsic characteristics of coagulants and flocculants such as high cationic charge density, long polymer chains, bridging of aggregates, and precipitation. The high content of positively charged amine groups in the chitosan structure facilitates electrostatic interaction between polymer chains and negatively charged algal cells, ${ }^{27,28}$ which caused rapid mitigation of cyanoHABs (Figure 3). For toxin producing cyano-HABs, most toxins are contained inside the cells during the bloom, which will be released and contributed to the dissolved MCs when the cells lysis occur. ${ }^{29}$ In the chitosan-MLS flocculation only systems, although $99 \%$ algal cells were removed from the water column at day 1 (Figure 3), dissolved MC-RR (Figure 4A-b), and MC-LR (Figure 4B-b) began to increase in the water column at day 12 and reached the maximum concentration during days $24-40$. This result suggests that flocculation alone 
can only remove algae cells from the water column; however, dissolved MC toxins may be significantly released if the algae flocs are not further treated. The algae flocs may be resuspended in the water and continue to grow under the field conditions especially in shallow waters. ${ }^{30}$ By using soil capping after the flocculation, the increase of dissolved MC-RR (Figure 4A-c) and MC-LR (Figure 4B-c) from the sediment was postponed about a week and reduced by 74 and $40 \%$ compared to the flocculation only treatment at day 40 . Soil capping not only physically sealed the algal cells in sediment and depressed the diffusion of dissolved MCs from the sediment to the water, but also significantly promoted the cells lysis (Figure S4, Supporting Information). Algal cell lysis is crucial for the reduction of algae recruitment; ${ }^{30}$ however, it will result in the release of intracellular MCs. ${ }^{29}$ If the released toxin is only buried under the capping layer but not degraded, it will be diffused into the water in a postponed period (Figure 4A-c, Figure 4B-c). Previous reports found that once the capping layer was saturated, the excessive toxins could eventually be released into water. ${ }^{31}$ The problems mentioned above can be solved if the capping layer is highly efficient for MCs degradation. Indeed, in the flocculation plus microorganism modified capping systems $(1 \mathrm{~cm})$, both MC-RR and MC-LR were almost entirely decomposed in the water (Figure 4A-d,Bd) and sediment (Figure 5A-d,B-d) throughout the tested period. By increasing the thickness of the Pseudomonas sp. An 18 modified capping layer, the microorganism may obtain more time to degrade the upcoming MCs molecules under the capping layer.

Adaptability of Incubated Microorganisms in Natural Environment. In cyano-HABs waters, degradation of MCs by the indigenous MC-degrading microorganism is one of the main pathways for toxins removal. ${ }^{32,33}$ In our simulated systems, the maximum dissolved MC-RR and MC-LR reached $108.14 \mu \mathrm{g} / \mathrm{L}$ (Figure 4A-a) and $15.45 \mu \mathrm{g} / \mathrm{L}$ (Figure 4B-a) during 40 days of incubation, suggesting that a long time was required for the removal of toxins by the native microorganism only. This agreed well with the report that MCs cannot be rapidly removed relying on the native MC-degrading microorganisms after an abrupt release of MCs under the collapse of severe cyano-HABs. ${ }^{19}$ Although exogenous MCs-degrading bacteria have been widely studied under laboratory conditions, one problem is that most of the incubated bacteria can hardly be sustainable in natural waters due to poor bacterial adaptability. ${ }^{34}$

The conventional approach of obtaining MC-degrading bacteria is collection of microorganism communities from MCs contaminated sediment or water, followed by enrichment and isolation in artificial medium (mostly mineral salts medium) where MCs were supplied as the sole carbon and nitrogen source. ${ }^{35}$ The discrepancy of chemical properties between artificial media and the natural environment, in addition to the competition with indigenous microorganism communities in natural environment, often results in poor bacterial adaptability of the incubated bacteria and limited toxins removal efficiency. ${ }^{36}$ To improve bacterial adaptability in natural waters, we proposed an isolation strategy using concentrated natural medium in our previous study, ${ }^{21}$ by which the obtained Pseudomonas sp. An18 showed enhanced adaptability and sustainability for MC degradation in sampled Taihu Lake water where continuously added MCs were degraded.
In flocculation only systems, dramatic increase of dissolved MC-RR and MC-LR occurred after nearly 14 days incubation (Figure 4A-b, Figure 4B-b). Despite the diffusion of released MCs can be largely reduced in soil capping treatment (Figure 4A-c, Figure 4B-c), the total residual toxins in the experimental systems were not significantly reduced compared to control (Figure 5). In contrast, the increase of dissolved MCs had entirely disappeared (Figure 4A-d, Figure 4B-d), the residual MC-RR (Figure 5A-d) and MC-LR (Figure 5B-d) in the whole sediment-water system displayed $90 \%$ reduction in Pseudomonas sp. An 18 microorganism modified soil treated systems, suggesting the adaptability of the incubated Pseudomonas sp. An18 strains and biodegradation of MCs in the experimental systems. In this study, Pseudomonas sp. An 18 was enriched from water extracts of sediment and experienced selective pressure and subsequent isolation in concentrated water extracts of sediment, which showed similar nutrient conditions, components, and $\mathrm{pH}$ with the real environment and led to the adaptation of reincubated microbes in the simulated natural water.

Concentrated Microorganisms and MCs by in Situ Flocculation-Capping. Biodegradation of MCs by exogenous MC-degrading bacteria under natural conditions requires not only the adaptation of bacteria, but also the reaction opportunity between the incubated bacteria and toxins. ${ }^{37}$ Direct addition of isolated bacteria into natural waters may encounter serious dilution problem. ${ }^{34}$ Embedding bacteria into soil can keep relative high bacterial biomass on the soil particles and therefore enhance its reactivity with the toxins. Moreover, in natural cyano-HABs waters, the algal cells, together with MCs, are predominant in the surface of water column, ${ }^{5}$ which may also impair the degradation reaction between toxins and bacteria. In comparison to 51\% MC-RR (Figure 5A-a) and 56\% MC-LR (Figure 5B-a) that were released and diluted in the water column in the control systems, 96\% MC-RR (Figure 5Ac) and $98 \%$ MC-LR (Figure 5B-c) were confined under the capping layer in flocculation-soil capping systems, thus providing concentrated MCs under the capping layer and suggesting that if MC-degrading bacteria can be embedded in the capping material, the biodegradation reaction may be enhanced due to the simultaneously raised toxins concentration and bacteria biomass in the sediment. In this study, the bacteria-modified soil loaded nearly $10^{15}$ Pseudomonas sp. An 18 cells/g modified soil (Figure S3, Supporting Information), indicating that a $1 \mathrm{~cm}$ thick capping layer (approximately 140 g) can embed $1.4 \times 10^{17}$ Pseudomonas sp. An 18 cells, creating a microenvironment with higher bacterial biomass. Furthermore, proliferation of Pseudomonas sp. An18 in the soil led to $10^{5}$ increases of bacteria number during 6 days of incubation (Figure 2), suggesting the soil favored bacteria inhabitation and proliferation.

Degradation of MCs by Flocculation-Microorganism Modified Soil Capping. In addition to providing adequate time for bacteria to establish biodegradation ability before they were mixed back to water column, flocculation-microorganism modified soil capping treatment also retained the released MCs within the confined sediment layer. Hence, the concentrated toxins and bacteria in situ increased the availability of toxins to Pseudomonas sp. An18, as the biodegradation efficiency was positively proportional to the initial toxin concentrations within a certain range; ${ }^{10,19}$ therefore, $90 \%$ degradation of MC-RR (Figure 5A-d) and MC-LR (Figure 5B-d) from the whole sediment-water systems were triggered. This is likely due to 
that when MCs are released and diffused into the microorganisms modified soil, the toxins are metabolized as carbon and nitrogen source by Pseudomonas sp. An18. This was confirmed by the analysis of MCs biodegradation products by MALDI-TOF mass spectra, which revealed that in Pseudomonas sp. An18 modified soil capped systems, the degradation products of MC-RR $\left(M_{\mathrm{w}}=332.92\right.$ and 707.27, Figure $\left.6 \mathrm{~b}\right)$ and MC-LR $\left(M_{\mathrm{w}}=332.73\right.$ and 301.65, Figure $\left.6 \mathrm{~d}\right)$ were evident as the concentration of MC-RR and MC-LR decreased in the experimental systems (Figure 5A-d and Figure 5B-d). Moreover, the appearance of $M_{\mathrm{w}}=332$, which was recognized as the Adda residues, ${ }^{38}$ in both the biodegradation products of MC$\mathrm{RR}$ and MC-LR, indicating that the cleavage of Adda-Arg peptide bond, by which the toxicity of MCs can be substantially reduced. ${ }^{39}$ Zhang et al. studied the biodegradation pathway of MC-RR bacterium Sphingopyxis sp. USTB-05, the results suggested that Adda-Arg peptide bond of MC-RR was cleaved, then a hydrogen and a hydroxyl were combined onto the $\mathrm{NH}_{2}$ group of Adda and the carboxyl group of arginine, ${ }^{35}$ during which the $M_{w}=332$ were indicated as the Adda residues. ${ }^{35,38}$ The examined $M_{\mathrm{w}}=332.92$ in the present test implies the similar biodegradation pathway of MCs by Pseudomonas sp. An18, which need further investigations.

In the column experiments, under the coeffects of prevented bacterial dilution (embedding Pseudomonas sp. An18 in the microorganism modified soil), concentrated MCs concentration in situ (flocculation and microorganism modified soil capping), as well as enhanced bacteria adaptability, the reduction of dissolved MCs (Figure 4) in water and the decomposition of MCs in the sediment can be achieved (Figure 5).

To unambiguously understand the role of incubated Pseudomonas sp. An18 and to exclude the biodegradation of MCs by the indigenous microorganism, we used autoclaved local soil instead of in situ sediment as sediment layer in the column. Under field conditions, natural aquatic sediments have a wide range of MC-degrading microorganisms, it is possible that the combined effects of indigenous bacteria in the natural sediment and Pseudomonas sp. An18 in the capping layer may influence the efficiency of MC degradation. In addition, this study was carried out in columns under stationary conditions, therefore the resuspension of sunken algal cells (Figure 3) and diffusion of the released MCs (Figure 4) were depressed through $1 \mathrm{~cm}$ thick soil or microorganism modifies soil capping. However, capping as a measure for lake restoration is inevitably influenced by the complicated conditions in the field, such as vertical transport and resuspension generated by bioturbation ${ }^{40}$ and horizontal transport induced by the wind and current. Although resuspension of algal flocs has been studied under simulated laboratory conditions, ${ }^{30}$ the complicated impact of field condition needs further studies at various scales including lab, mesocosm, whole water ponds, and open waters.

Environmental Implications. The cyano-HABs in eutrophic lakes are usually followed by the release of toxins due to the decomposition of algal cells. The dissolved MCs in many cyano-HABs lakes can remain a few micrograms per liter $(\mu \mathrm{g} /$ L), ${ }^{5,41}$ but the toxins can be accumulated in zooplankton, aquatic organisms, and, eventually, bioaccumulated in human bodies through food chain. ${ }^{42}$ Only when MCs are degraded to less toxic products can the negative effect be diminished. ${ }^{16}$ In this study, the flocculation-capping technology converged algal cells coupled with intracellular toxins under the capping layer, accelerated algae decomposition, which reduced the recruit- ment of algae cell and potentially promoted the transfer of released nutrients from algae cells to vegetation if submerged vegetation seeds were included in the capping material in shallow waters. Different methods should be jointly used to achieve both short-term and long-term effects. For instance, flocculation is important to remove toxic algae from water and create the light conditions for the vegetation restoration in shallow water systems. The problems of floc resuspension and algal toxin release associated with flocculation method can be compromised by using a microorganism-modified soil/sand capping method. The capping method is also important for maintaining water clarity for an extended period so that it may create a window period for the restoration of submerged vegetation, and thus, the remediation processes can be relayed into a longer term. Once the excess nutrients are redistributed from water to sediment and from algae to vegetation, the restoration of a healthy food chain and aquatic ecology may become possible by using the nutrients as a resource. As the released toxins were biodegraded, it is possible to diminish the risk of toxin accumulation in aquatic vegetation, organisms and animals, which may further impact the food web and public health, which needs further multidisciplinary long-term studies.

\section{ASSOCIATED CONTENT}

\section{Supporting Information}

Jar test for cyano-HABs removal using chitosan modified soil; assessment of Pseudomonas sp. An18 carrying capacity of microorganism modified soil; embedding capability of Pseudomonas sp. An18 on the microorganism modified soil; and morphology characterization of algal cells. The Supporting Information is available free of charge on the ACS Publications website at DOI: 10.1021/acs.est.5b00840.

\section{AUTHOR INFORMATION}

\section{Corresponding Author}

*E-mail: gpan@rcees.ac.cn. Tel: +8610 62849686. Fax: +86 10 62923541 .

\section{Notes}

The authors declare no competing financial interest.

\section{ACKNOWLEDGMENTS}

The research was supported by the Strategic Priority Research Program of CAS (XDA09030203) and science promotion program of Research Center for Eco-environmental Sciences, CAS (YSW2013B05).

\section{REFERENCES}

(1) Paerl, H. W.; Otten, T. G. Blooms bite the hand that feeds them. Science 2013, 342 (6157), 433-434.

(2) Otten, T. G.; Xu, H.; Qin, B.; Zhu, G.; Paerl, H. W. Spatiotemporal patterns and ecophysiology of toxigenic microcystis blooms in Lake Taihu, China: Implications for water quality management. Environ. Sci. Technol. 2012, 46 (6), 3480-3488.

(3) Magalhães, V. F.; Marinho, M. M.; Domingos, P.; Oliveira, A. C.; Costa, S. M.; Azevedo, L. O.; Azevedo, S. M. F. O. Microcystins (cyanobacteria hepatotoxins) bioaccumulation in fish and crustaceans from Sepetiba Bay (Brasil, RJ). Toxicon 2003, 42 (3), 289-295.

(4) Chen, W.; Song, L.; Peng, L.; Wan, N.; Zhang, X.; Gan, N. Reduction in microcystin concentrations in large and shallow lakes: Water and sediment-interface contributions. Water. Res. 2008, 42 (3), $763-773$.

(5) Song, L.; Chen, W.; Peng, L.; Wan, N.; Gan, N.; Zhang, X. Distribution and bioaccumulation of microcystins in water columns: $\mathrm{A}$ systematic investigation into the environmental fate and the risks 
associated with microcystins in Meiliang Bay, Lake Taihu. Water. Res. 2007, 41 (13), 2853-2864.

(6) Paerl, H.; Otten, T. Harmful cyanobacterial blooms: Causes, consequences, and controls. Microb. Ecol. 2013, 65 (4), 995-1010.

(7) Poste, A. E.; Hecky, R. E.; Guildford, S. J. Evaluating microcystin exposure risk through fish consumption. Environ. Sci. Technol. 2011, 45 (13), 5806-5811.

(8) Barrington, D. J.; Reichwaldt, E. S.; Ghadouani, A. The use of hydrogen peroxide to remove cyanobacteria and microcystins from waste stabilization ponds and hypereutrophic systems. Ecol. Eng. 2013, 50, 86-94.

(9) Tang, Y.; Zhang, H.; Liu, X.; Cai, D.; Feng, H.; Miao, C.; Wang, X.; Wu, Z.; Yu, Z. Flocculation of harmful algal blooms by modified attapulgite and its safety evaluation. Water. Res. 2011, 45 (9), 28552862.

(10) Ghernaout, B.; Ghernaout, D.; Saiba, A. Algae and cyanotoxins removal by coagulation/flocculation: A review. Desalin. Water. Treat. 2010, 20 (1-3), 133-143.

(11) Pei, H. Y.; Ma, C. X.; Hu, W. R.; Sun, F. The behaviors of Microcystis aeruginosa cells and extracellular microcystins during chitosan flocculation and flocs storage processes. Bioresour. Technol. 2014, 151, 314-322.

(12) Lürling, M.; Faassen, E. J. Controlling toxic cyanobacteria: Effects of dredging and phosphorus-binding clay on cyanobacteria and microcystins. Water. Res. 2012, 46 (5), 1447-1459.

(13) Kim, B. H.; Lee, J. H.; Hwang, S. J. Removal of Cyanobacteria and Microcystin by Natural Plant-Mineral Combinations in Eutrophic Waters. B. Eenviron. Contam.Tox. 2013, 90 (2), 216-221.

(14) Ho, L.; Lambling, P.; Bustamante, H.; Duker, P.; Newcombe, G. Application of powdered activated carbon for the adsorption of cylindrospermopsin and microcystin toxins from drinking water supplies. Water. Res. 2011, 45 (9), 2954-2964.

(15) Pouria, S.; de Andrade, A.; Barbosa, J.; Cavalcanti, R. L.; Barreto, V. T. S.; Ward, C. J.; Preiser, W.; Poon, G. K.; Neild, G. H.; Codd, G. A. Fatal microcystin intoxication in haemodialysis unit in Caruaru, Brazil. Lancet 1998, 352 (9121), 21-26.

(16) Jones, G. J.; Orr, P. T. Release and degradation of microcystin following algicide treatment of a Microcystis aeruginosa bloom in a recreational lake, as determined by HPLC and protein phosphatase inhibition assay. Water. Res. 1994, 28 (4), 871-876.

(17) Pan, G.; Yang, B.; Wang, D.; Chen, H.; Tian, B. H.; Zhang, M. L.; Yuan, X. Z.; Chen, J. In-lake algal bloom removal and submerged vegetation restoration using modified local soils. Ecol. Eng. 2011, 37 (2), 302-308.

(18) Zhu, L.; Wu, Y.; Song, L.; Gan, N. Ecological dynamics of toxic Microcystis spp. and microcystin-degrading bacteria in Dianchi Lake, China. Appl. Environ. Microbiol. 2014, 80 (6), 1874-1881.

(19) Cai, Z.; Zhou, Q.; Peng, S.; Li, K. Promoted biodegradation and microbiological effects of petroleum hydrocarbons by Impatiens balsamina L. with strong endurance. J. Hazard. Maters. 2010, 183 (1-3), 731-737.

(20) Zhao, G.; Zhou, L.; Li, Y.; Liu, X.; Ren, X. Enhancement of phenol degradation using immobilized microorganisms and organic modified montmorillonite in a two-phase partitioning bioreactor. $J$. Hazard. Maters. 2009, 169 (1-3), 402-10.

(21) Li, H.; Pan, G. Enhanced and continued degradation of microcystins using microorganisms obtained through natural media. J.Microbiol. Meth. 2014, 96 (1), 73-80.

(22) Zou, H.; Pan, G.; Chen, H.; Yuan, X. Removal of cyanobacterial blooms in Taihu Lake using local soils II. Effective removal of Microcystis aeruginosa using local soils and sediments modified by chitosan. Environ. Pollut. 2006, 141 (2), 201-205.

(23) Ghiaci, M.; Aghaei, H.; Soleimanian, S.; Sedaghat, M. E. Enzyme immobilization: Part 2: Immobilization of alkaline phosphatase on Nabentonite and modified bentonite. Appl. Clay. Sci. 2009, 43 (3-4), $308-316$.

(24) Cong, L. M.; Huang, B. F.; Chen, Q.; Lu, B. Y.; Zhang, J.; Ren, Y. P. Determination of trace amount of microcystins in water samples using liquid chromatography coupled with triple quadrupole mass spectrometry. Anal. Chim. Acta 2006, 569 (1-2), 157-168.

(25) Chen, W.; Li, L.; Gan, N.; Song, L. Optimization of an effective extraction procedure for the analysis of microcystins in soils and lake sediments. Environ. Pollut. 2006, 143 (2), 241-6.

(26) Yan, H.; Pan, G.; Zhang, M.; Chen, H.; Zou, H. Study on the extraction and purification of microcystins. Acta Scientiae Circumstantiae 2004, 24 (2), 355-359.

(27) Li, L.; Pan, G. A universal method for flocculating harmful algal blooms in marine and fresh waters using modified sand. Environ. Sci. Technol. 2013, 47 (9), 4555-4562.

(28) Pan, G.; Chen, J.; Anderson, D. M. Modified local sands for the mitigation of harmful algal blooms. Harmful Algae 2011, 10 (4), 381387.

(29) Zamyadi, A.; Ho, L.; Newcombe, G.; Bustamante, H.; Prévost, M. Fate of toxic cyanobacterial cells and disinfection byproducts formation after chlorination. Water. Res. 2012, 46 (5), 1524-1535.

(30) Pan, G.; Dai, L.; Li, L.; He, L.; Li, H.; Bi, L.; Gulati, R. D. Reducing the recruitment of sedimented algae and nutrient release into the overlying water using modified soil/sand flocculation-capping in eutrophic lakes. Environ. Sci. Technol. 2012, 46 (9), 5077-5084.

(31) Sun, H.; Xu, X.; Gao, G.; Zhang, Z.; Yin, P. A novel integrated active capping technique for the remediation of nitrobenzenecontaminated sediment. J. Hazard. Maters. 2010, 182 (1-3), 184-190.

(32) Chen, X.; Yang, X.; Yang, L.; Xiao, B.; Wu, X.; Wang, J.; Wan, $H$. An effective pathway for the removal of microcystin LR via anoxic biodegradation in lake sediments. Water. Res. 2010, 44 (6), 18841892.

(33) Ho, L.; Hoefel, D.; Palazot, S.; Sawade, E.; Newcombe, G.; Saint, C. P.; Brookes, J. D. Investigations into the biodegradation of microcystin-LR in wastewaters. J. Hazard. Maters. 2010, 180 (1-3), $628-633$.

(34) Jones, G. J.; Bourne, D. G.; Blakeley, R. L.; Doelle, H. Degradation of the cyanobacterial hepatotoxin microcystin by aquatic bacteria. Nat. Tox. 1994, 2 (4), 228-235.

(35) Zhang, M.; Pan, G.; Yan, H. Microbial biodegradation of microcystin-RR by bacterium Sphingopyxis sp. USTB-05. J. Environ. Sci. 2010, 22 (2), 168-175.

(36) Megharaj, M.; Ramakrishnan, B.; Venkateswarlu, K.; Sethunathan, N.; Naidu, R. Bioremediation approaches for organic pollutants: A critical perspective. Environ. Int. 2011, 37 (8), 13621375.

(37) Farhadian, M.; Vachelard, C.; Duchez, D.; Larroche, C. In situ bioremediation of monoaromatic pollutants in groundwater: A review. Bioresour. Technol. 2008, 99 (13), 5296-5308.

(38) Edwards, C.; Graham, D.; Fowler, N.; Lawton, L. A. Biodegradation of microcystins and nodularin in freshwaters. Chemosphere 2008, 73 (8), 1315-1321.

(39) Park, H. D.; Sasaki, Y.; Maruyama, T.; Yanagisawa, E.; Hiraishi, A.; Kato, K. Degradation of the cyanobacterial hepatotoxin microcystin by a new bacterium isolated from a hypertrophic lake. Environ. Toxicol. 2001, 16 (4), 337-343.

(40) Meis, S.; Spears, B. M.; Maberly, S. C.; O’Malley, M. B.; Perkins, R. G. Sediment amendment with Phoslock in Clatto Reservoir (Dundee, UK): Investigating changes in sediment elemental composition and phosphorus fractionation. J. Environ. Manage. 2012, 93 (1), 185-193.

(41) Papadimitriou, T.; Kagalou, I.; Stalikas, C.; Pilidis, G.; Leonardos, I. Assessment of microcystin distribution and biomagnification in tissues of aquatic food web compartments from a shallow lake and evaluation of potential risks to public health. Ecotoxicology 2012, 21 (4), 1155-1166.

(42) Zhang, D.; Xie, P.; Liu, Y.; Qiu, T. Transfer, distribution, and bioaccumulation of microcystins in the aquatic food web in Lake Taihu, China, with potential risks to human health. Sci. Total Environ. 2009, 407 (7), 2191-2199. 